Ophthalmologe 2009 · 106:495-495

DOI 10.1007/s00347-008-1886-9

Online publiziert: 4. Juni 2009

(c) Springer Medizin Verlag 2009

H.J. Bolz

Institut für Humangenetik, Universitätsklinikum Köln

\title{
Aktueller Stand der Wissenschaft des Usher-Syndroms
}

dieses genetischen Subtyps ist sehr variabel und kann in einigen Fällen als USH1 imponieren.

Die in der Regel schwerwiegende Beeinträchtigung von Hören und Sehen hat erhebliche Konsequenzen für Betroffene. Es wird deshalb nach Wegen gesucht, die Erkrankung zu behandeln oder die Patienten zumindest optimal zu unterstützen. Gerade wegen der starken Beeinträchtigung des visuellen Systems sollten die differenzierten Möglichkeiten der Rehabilitation des auditorischen Systems von digitalen, teil- und vollimplantierbaren Hörgeräten bis hin zu Kochleaimplantaten ausgeschöpft werden.

Die Identifizierung der verantwortlichen Gene spielt beim Usher-Syndrom eine große Rolle. Sie ist Voraussetzung, um ggf. schon im frühen Kindesalter einschätzen zu können, ob der angeborenen Hörstörung später eine Netzhautdegeneration folgen wird. Darüber hinaus führt die Charakterisierung der beteiligten Gene und der durch sie kodierten Proteine zu einem besseren Verständnis der molekularen Prozesse, die zur Erkrankung führen. Das gerade in den letzten Jahren stark zunehmende Interesse an der Pathophysiologie von Ziliopathien wird dies noch weiter unterstützen. Zum Erkenntnisfortschritt auf diesem Gebiet hat die europäische (und hier wiederum die deutsche) Forschung bisher erheblich beigetragen.

Der erste Übersichtsartikel geht auf die molekularen Grundlagen des Usher-Syndroms ein und hebt den schon jetzt anwendbaren Nutzen, aber auch Probleme bei der molekulargenetischen Diagnosestellung hervor. In einem zweiten Ar- tikel werden das typische klinische Erscheinungsbild, die diagnostisch wegweisenden Untersuchungsbefunde und die aktuellen Therapieoptionen sowohl aus augenärztlicher als auch aus HNO-ärztlicher Sicht vorgestellt.

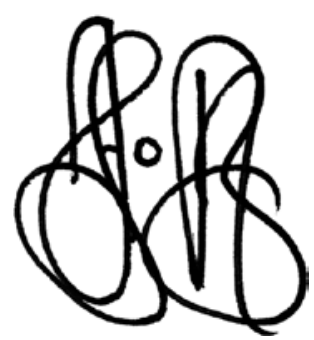

H. J. Bolz

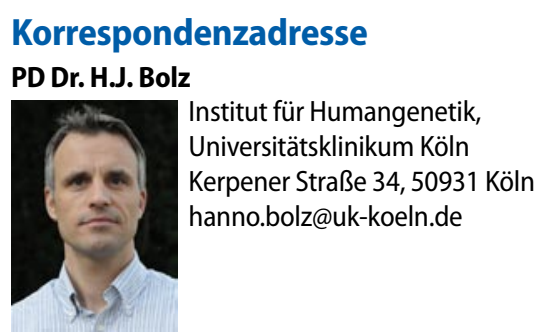

